\title{
Part Deployment Model using Combined Quality Function Deployment and Cybernetic Fuzzy Analytic Network Process
}

\author{
Farahbod Mohammadi ${ }^{1}$, Fatemeh Nateghi ${ }^{1}$, Seyed Pourya Pourhejazi ${ }^{2}$, Arham Abdullah ${ }^{3 *}$ \\ Nouredin Gandomi ${ }^{4}$ and Mohammadali Kazerooni Sadi ${ }^{1}$ \\ 'Department of Structure \& Materials, Faculty of Civil Engineering, Universiti Teknologi Malaysia, Johor, 81310, \\ Malaysia; farahbod63@gmail.com, nateghi.f@gamil.com, kazerooni.ma@gmail.com \\ 2Department of Manufacturing \& Industrial Engineering, Faculty of Mechanical Engineering, Universiti Teknologi \\ Malaysia, Johor, 81310, Malaysia; pouryaphejazy@gmail.com \\ ${ }^{3}$ Associated Professor of Civil Enginnering, Department of Structure \& Materials, Faculty of Civil \\ Engineering, Universiti Teknologi Malaysia, Johor, 81310, Malaysia; arham@utm.my \\ ${ }^{4}$ Civil Engineering Department, Research Institute of Shakhes Pajouh, Isfahan, Iran; jhdgandomi@yahoo.com
}

\begin{abstract}
Quality Function Deployment (QFD) is a customer oriented design tool used to ensure that customer expectations are satisfied in the early design stage. Customers directly and companies indirectly enjoy the benefits of implementing such methodology. Many extensions have been proposed in order to extend QFD's application or improve limitation of traditional QFD; among which incorporation of Multi-Criteria Decision Making (MCDM) theories into QFD, in particular Analytic Network Process (ANP) is noteworthy. This paper proposes a new extension of QFD called Fuzzy Cybernetic ANP (FCANP) which is able to model QFD tables, especially when company's experts deal with a large number of customer demands, while subjectivity of judgments are handled.
\end{abstract}

Keywords: Fuzzy Cybernetic Analytic Network Process (FCANP), Part Deployment, Quality Function Deployment (QFD)

\section{Introduction}

Global competitiveness in today's world is an undeniable necessity of every industrial firm. This fact is not limited to industry and goods production; indeed, it includes all customer-oriented organizations where the customers play a vital role to identify organizational positive and negative aspects ${ }^{1}$. They try to achieve better quality and less cost for the products. For this reason, many companies meet the challenges, which are related to various customer demands, and its rapid changes; they must be able to respond quickly to stay in the competitive market. With the emergence of competition, customer satisfaction was considered as the most important issue, and the concept of customer demands (WHATs) produced.
WHAT is a term used broadly in business, it is used to illustrate the identification process of customer's needs and aversions, and consider these in designing the product.

By focusing on WHATs, QFD has been utilized as a powerful approach to meet customer demands, especially at the product design phase. It systematically translates WHATs into proper company requirements in all stages from product development to engineering and manufacturing stage, marketing and sales, and also distribution ${ }^{2}$.

Conventional QFD, however, has its limitations. Many customized QFD models have been proposed among which integration of Goal Programming, Analytic Hierarchy Process (AHP), Fuzzy logic, Expert

${ }^{*}$ Author for correspondence: 
System, Data Envelopment Analysis (DEA), Dynamic QFD, and Analytic Network Process (ANP) are noteworthy ${ }^{3}$.

One of the widely used methods is to integrate ANP into QFD. The reason is because ANP is not only able to prioritize customer demands, but also able to view the whole QFD process as a decision problem ${ }^{4}$. Nevertheless, ANP highly depends on human judgment, and human brain limits to precisely compare a large number of decision elements in pair. In addition, subjectivity is an inherent part of human judgment that affects accuracy of decision-making result. The above issues become worse when ANP is applied as an extension of QFD where company's decision makers are required to satisfy a large number of customer demands. In response to the above limitations, while facilitating pairwise comparison of elements of QFD tables in order to derive priority of Part Characteristics (PCs), this study attempts to use a fuzzy cybernetic ANP model as a novel extension of QFD to handle subjectivity of judgments pairwise.

The paper has been organized as follows: Section 2 briefly reviews existing literature on QFD, ANP-QFD and highlights the gap when ANP is incorporated into QFD. Section 3 describes proposed model of FCANPQFD. Section 4 illustrates a methodology of this paper on a case study, and finally Section 5 concludes this paper and made some recommendations.

\section{Relevant Studies on QFD and ANP-QFD}

Benefits of QFD are not limited to customer satisfaction, rather QFD enables the company to assign their resources and organize skills based on customer requirements, and, therefore, it would lead to lower production costs by ignoring features with low priority from the customer's perspective. Its organized environment also evaluates the essential choices from alters and expansion at the starting point of the design process and decreasing the mid project modifications. QFD attracts the customers, which result in more selling rates resulting in higher revenues. In this manner, QFD utilizes the whole expansion procedure, minimizing the modifications and waste throughout this stage, and as a result, time optimization is needed for presenting a new product and/or service to the marketplace ${ }^{5}$.
There are two main QFD types; the first one is the Four-Phase model. It consists of four interconnected tables, which start with House of Quality (HoQ) or product planning, followed by part deployment, process planning, and production planning phase. The complete Four-Phase model has been described and illustrated ${ }^{6}$; The second deployment is based on Akao's Matrix ${ }^{2}$. Although, these models differ in term of deployment style, they are similar in concept. However, the FourPhase model is more popular ${ }^{7}$. While Four-Phase model represents a complete QFD process, most research only put focus on product planning, the first phase of $\mathrm{QFD}^{8}$.

Traditionally, customer demands are collected through survey, and then customers are asked to prioritise their needs. Important customer demands are, then, entered into HoQ. Since, the customer needs are usually vague, they should be meaningfully translated into technical measures. Technical measures or HOWs are the way in which WHATs are technically answered. One HOW may answer to only a WHAT. On the other side, it is either possible, one HOW satisfies a number of WHATs. There is also correlation between WHATs, which should be taken into account during the quantification process of HoQ. In order to optimally satisfy customer needs, correlation between HOWs should also be seen. This is because; answering to one customer need may negatively affect other customer needs. The first stage of QFD like an engine derives priority to HOWs through a systematic process. The HoQ is the predecessor of part development table, where technical measures are translated into essential part characteristics. Similar to HoQ, part deployment table derives priority of PCs. Figure 1 shows both HoQ and part deployment stages along with their elements.

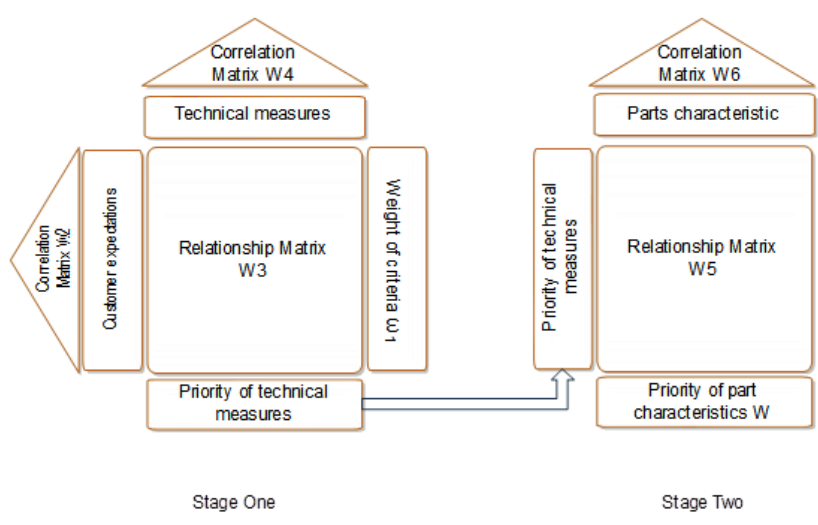

Figure 1. Deployment of two stage QFD tables. 
Interestingly, if the elements in the roof and porch of QFD tables are respectively regarded as decision alternatives and criteria, QFD can be viewed as Multi-Criteria Decision Making (MCDM) tool since it derives priority to decision alternatives. On the other side, alternatives are prioritised against weighted criteria; therefore, MCDM has been combined with QFD for the purpose of prioritisation. Probably, AHP is the first MCDM theory integrated with QFD to prioritise customer needs, and decision alternatives ${ }^{9-11}$. However, the concept behind AHP based decision-making is hierarchal modelling of decision problem in which dependence and feedback as an inherent nature of QFD tables were not considered. Later, the AHP generalized into ANP that was able to solve more complex decision problem. In addition, supermatrix approach was replaced with additive synthesis to derive final decision alternatives ${ }^{12}$. The work of Karsak et $\mathrm{al}^{5}$ was the pioneer research where ANP is used to model product planning table. However, since 2003 , in contrast to other available QFD extensions, which is being widely used ${ }^{3}$, very few studies ${ }^{8,13-20}$ adopted ANP and incorporated it into QFD. Review of aforementioned ANP in QFD works reveals researchers generally following either simple matrix manipulation or supermatrix approach to estimate final priority of decision alternatives. Meanwhile, fuzzy set theory in several works integrated with the ANP to handle subjectivity of human judgments.

Undoubtedly, there is nothing wrong with the logic behind ANP, however, when a decision problem with a large number of decision criteria, and alternatives is solved with the aid of ANP, this is the inability of the human brain that cannot precisely perform such a large number of pairwise comparisons. It is noteworthy to mention, all above, ANP in QFD models were demonstrated with a simple and small case studies whose number of customer needs and technical measures are less than six. However, in real world QFD cases, a team of experts usually faces with a large number of customer demands, and technical measures. As a result, an extension like conventional ANP that is based on pairwise comparison falls short to model such a QFD tables with large data. Therefore, the methodology of this study aims to propose a new extension that is compatible with real world QFD cases whose decision makers deal with large customer demands, technical measures, and subsequently, product characteristics.

\section{Methodology}

This section presents the modelling framework of implementing QFD up to part deployment phase based on the fuzzy cybernetic ANP model in which supermatrix approach is employed to estimate priority of decision alternatives. The model is based on three steps, namely, problem decomposition or depicting network of interactions, knowledge acquisition and analysis. The steps are demonstrated in Figure 2 and discussed in detail.

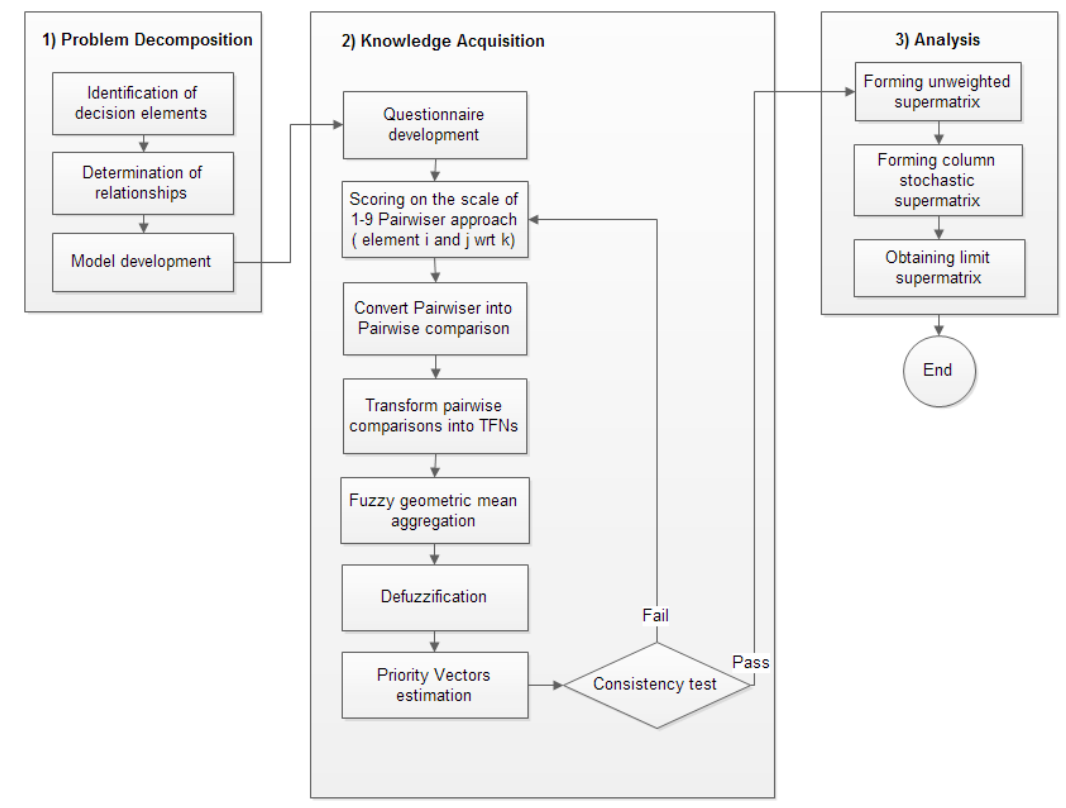

Figure 2. Framework of FCANP-QFD. 


\subsection{Problem Decomposition}

Since the first two tables of QFD are considered as decision problem, the initial step is to identify effective components of model. In both tables, WHATs and HOWs, relationship matrix between HOWs and WHATs, and two separate correlation matrix for HOWs and WHATs are regarded as decision components. Then, a focus group is usually conducted, and participants who are company's experts are asked to identify existent inner and outer-relationships between QFD components. When the dependences are identified, as shown in Figure 3 , the decision network including goal, criteria (WHATs), sub-criteria (HOWs), Alternatives (PCs) together with their connections is illustrated.

\subsection{Knowledge Acquisition}

Following the network of interactions, judgments are elicited with the aid of questionnaire for the purpose of estimating local priority vectors. The pairwise comparison is the heart of ANP/AHP in which one compares two elements in terms of dominance ${ }^{21,22}$. In conventional pair-wise comparison, respondents are asked to answer this question; given a pair of elements, with respect to the third element, which one of these two elements is more dominant? The response to the question is based on Saaty's 1-9 scale where 1 and 9 indicate equally and the overwhelming dominance of element $i$ over $j$ However, in this study instead of pairwise comparison, pairwiser is employed.

The pairwiser $^{27}$ was first introduced as a novel approach for data collection of ANP/AHP in response to the bottleneck problem of data collection work load and inconsistency of judgments when a large number of decision elements should be pairwise compared. His model is called Cybernetic Analytic Network Process (CANP) whereby, instead of comparison of influential elements in pair with respect to a common property, a set of questions are prepared, and experts are asked to score influential elements in term of dominance on the scale of 1-9 where 1 and 9 represent, not important and extremely important respectively.

The CANP was developed based on crisp judgments. However, no human judgment is perfect, and the subjectivity is the inherent part of human judgment, especially during deployment of QFD tables where group of experts are involved in decision making process. Therefore, this paper incorporates fuzzy set theory, and with the aid of triangular fuzzy numbers (TFNs) whose membership function is adopted from the work of Lee and $\mathrm{Lin}^{23}$, which proposes a new extension based on Fuzzy Cybernetic Analytic Network Process (FCANP).

The difference between FCANP and CANP model is the fuzzification step. Once the judgments on the scale of 1-9 are elicited, according to the defined rules shown in Table 1 judgments are transformed into fuzzy linguistic variables. Then pairwiser comparison matrixes are formed based on corresponding TFNs. Clearly, when a group of K experts are involved in decision making process, $\mathrm{K}$ fuzzy pairwiser comparison matrixes are obtained. In order to estimate priority vectors, $\mathrm{K}$ fuzzy matrixes are aggregated with the aid of geometric mean. In addition, since priority vectors are obtained by solving the Equation (1) which has been defined for crisp matrixes, aggregated fuzzy comparison matrix are defuzzified with Centre of Gravity (COG) method ${ }^{24}$. Reasonably after estimation of priority vectors, consistency test (CR) is conducted as proof of reliability of judgment ${ }^{25}$. Experts whose judgments are identified as inconsistent, should be asked to revise their judgments in order to improve consistency ratio.

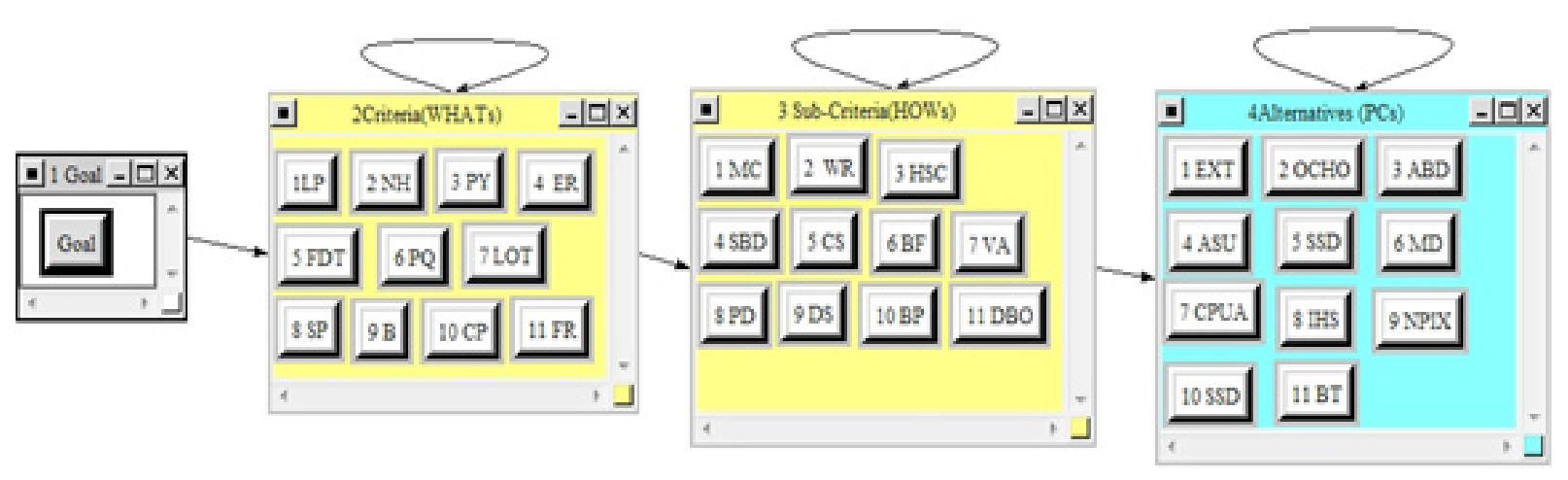

Figure 3. Structure of QFD network. 
Table 1. Pairwiser rules

\begin{tabular}{|c|c|c|}
\hline Scores $: \mathbf{i}$ and $j$ & Rules & TFN \\
\hline $\begin{array}{l}1=\text { Not } \\
\text { important }\end{array}$ & $\begin{array}{l}\text { IF PC }=i: j \text { and } i-j= \\
0 \text { THEN LVi:j =Equal } \\
\text { dominant }\end{array}$ & $(1,1,1)$ \\
\hline $2=$ Not to & IF PC $=i: j$ and $i-j=1$ & \\
\hline $\begin{array}{l}\text { Moderately } \\
\text { important }\end{array}$ & $\begin{array}{l}\text { THEN LVi:j = Equal to } \\
\text { moderate dominant }\end{array}$ & $(1,2,3)$ \\
\hline $\begin{array}{l}3=\text { Moderately } \\
\text { important }\end{array}$ & $\begin{array}{l}\text { IF PC }=i: j \text { and } i-j \\
=2 \text { THEN LVi:j }= \\
\text { Moderately dominant }\end{array}$ & $(2,3,4)$ \\
\hline $\begin{array}{l}4=\text { Moderately } \\
\text { to } \\
\text { Strongly } \\
\text { important }\end{array}$ & $\begin{array}{l}\text { IF PC }=\mathrm{i}: \mathrm{j} \text { and } \mathrm{i}-\mathrm{j}=3 \\
\text { THEN LVi:j= Moderately } \\
\text { to strongly dominant }\end{array}$ & $(3,4,5)$ \\
\hline $\begin{array}{l}5=\text { Strongly } \\
\text { important }\end{array}$ & $\begin{array}{l}\text { IF PC }=i: j \text { and } i-j= \\
4 \text { THEN LVi:j= Strongly } \\
\text { dominant }\end{array}$ & $(4,5,6)$ \\
\hline $\begin{array}{l}6=\text { Strongly to } \\
\text { very } \\
\text { Strongly } \\
\text { important }\end{array}$ & $\begin{array}{l}\text { IF PC }=\mathrm{i}: \mathrm{j} \text { and } \mathrm{i}-\mathrm{j}=5 \\
\text { THEN LVi:j= Strong to } \\
\text { very strong dominant }\end{array}$ & $(5,6,7)$ \\
\hline $\begin{array}{l}\text { 7=Very strongly } \\
\text { important }\end{array}$ & $\begin{array}{l}\text { IF PC }=i: j \text { and } i-j= \\
6 \text { THEN LVi:j= Very } \\
\text { strong dominant }\end{array}$ & $(6,7,8)$ \\
\hline $\begin{array}{l}8=\text { Very strongly } \\
\text { to } \\
\text { Extremely } \\
\text { important }\end{array}$ & $\begin{array}{l}\text { IF PC }=i: j \text { and } i-j= \\
7 \text { THEN LVi:j= Very } \\
\text { strong to extremely } \\
\text { dominant }\end{array}$ & $(7,8,9)$ \\
\hline $\begin{array}{l}9=\text { Extremely } \\
\text { important }\end{array}$ & $\begin{array}{l}\text { IF PC }=i: j \text { and } i-j=8 \\
\text { THEN LVi:j= Extremely } \\
\text { dominant }\end{array}$ & $(9,9,9)$ \\
\hline
\end{tabular}

where LV and PC stand for linguistic variable and pairwise comparison respectively

$$
\text { A. } W=\lambda_{\max } \cdot \mathrm{W}
$$

where, $\mathrm{A}$ is the crisp value comparison matrix, $\mathrm{w}$ is the eigenvector and $\lambda_{\max }$ is the largest Eigen Value of $A$.

\subsection{Supermatrix Formation and Analysis}

The supermatrix is a holistic approach which represents how much an element on the left side of matrix can have influence on an element on the top of matrix ${ }^{12}$. In this paper, the following supermatrix represents how two stage QFD tables are modelled in ANP.

$W=\left[\begin{array}{ccccc} & \text { Goal } & \text { Criteria } & \text { Sub-criteria } & \text { Alternatives } \\ \text { Goal } & 0 & 0 & 0 & 0 \\ \text { Criteria } & \omega 1 & W 2 & 0 & 0 \\ \text { Sub-criteria } & 0 & W 4 & W 3 & 0 \\ \text { Alternatives } & 0 & 0 & W 6 & W 5\end{array}\right]$

Three stages should be followed in order to estimate final priority of decision alternatives; transferring all estimated priority vectors into corresponding cells and forming unweighted supermatrix, normalizing each column of unweighted supermatrix in order to obtain column stochastic matrix, and rising this matrix to power of large arbitrary number to obtain limit supermatrix where final priority of decision alternatives with respect to goal are obtained.

\subsection{Illustrative Example}

In this study, implementation of QFD up to part deployment stage for a laptop manufacturer company whose market focuses on university students was regarded as a case study. The three steps of the methodology were applied to the case study as follows. To hear the voice of customers interview, telephone survey was conducted with 20 students who were selected randomly. During the interview session, they were asked to express their expectations. A preliminary list of 15 customer demands was created. Next, with the aid of questionnaire the initial list was verified and validated. The aim of this step is to ensure that customer did not emotionally respond, and their real voice is heard. Hence, 4 unimportant demands were identified and the final list of 11 customer needs was given to the company. Then, focus groups of 5 technical experts were formed and participants were asked to determine part characteristics as well as technical measures for each and every customer demand. Once the decision elements entirely identified, the participants were asked to find relationships and correlations between them.

It is obviously possible to obtain 5 different networks since experts might have different opinion about the relationships and correlations. In this case study, the same situation happened. In order to reach a consensus, experts were asked to give at least one logical reason for each connection they made. The connections regarded acceptable if at least 3 participants agreed upon the given reason. Then, with the aid of The Super decision software network of interactions were depicted ${ }^{26}$. Table 2 and Figure 1 show the decision components and network model of this case study respectively.

For the purpose of knowledge acquisition, since two different target groups were involved in the decision making process, two sets of questions were designed, one for students in which they were asked 
Table 2. QFD elements with abbreviations

\begin{tabular}{|c|c|c|c|c|c|c|}
\hline NO & WHATs & NODE & HOWs & NODE & PCs & NODE \\
\hline 1 & lower price & LP & manufacturing cost & $\mathrm{MC}$ & externalization & EXT \\
\hline 2 & portability & PY & weight reduction & WR & $\begin{array}{l}\text { on-board chipset } \\
\text { optimization }\end{array}$ & $\mathrm{OCHO}$ \\
\hline 3 & easy to repair & ER & $\begin{array}{l}\text { better hardware and } \\
\text { software compatibility }\end{array}$ & HSC & aluminium body design & $\mathrm{ABD}$ \\
\hline 4 & fast data transfer & FDT & slow battery drain & SBD & auto diagnosis \& update & ASU \\
\hline 5 & product quality & PQ & customer service & CS & smaller size design & SSD \\
\hline 6 & $\begin{array}{l}\text { long operating } \\
\text { time }\end{array}$ & LOT & better finishing & $\mathrm{BF}$ & $\begin{array}{l}\text { High-tech material } \\
\text { development }\end{array}$ & $\mathrm{MD}$ \\
\hline 7 & support & SP & wider viewing angle & VA & CPU architecture & CPUA \\
\hline 8 & beauty & $\mathrm{B}$ & product durability & $\mathrm{PD}$ & number of pixels & NPIX \\
\hline 9 & clear picture & $\mathrm{CP}$ & drive speed & DS & In-home service & HIS \\
\hline 10 & fast response & FR & better process & $\mathrm{BP}$ & SSD hard disk & SSD \\
\hline 11 & no hang & $\mathrm{NH}$ & $\begin{array}{l}\text { display brightness } \\
\text { optimization }\end{array}$ & $\mathrm{DBO}$ & backlit & $\mathrm{BT}$ \\
\hline
\end{tabular}

to prioritise their expectations; and the second one designed to acquire the knowledge of focus group's participants. The responses were made on the scale of $1-9$, following the framework of pairwiser approach (Table 1). Once the pairwisers finished, the results were translated from crisp into fuzzy linguistic variables. Then, in order to aggregate different responses, geometric mean of answers was calculated; prior to use Equation (1), fuzzy judgments were transformed into crisp values and then by solving Equation (1) vectors of priority were estimated. Finally, consistency of judgments was tested to measure accuracy of estimated priorities.

The knowledge acquisition process when four decision elements, viz., 'slow battery drains', 'better process', 'display brightness optimization' and 'better hardware and software compatibility' are compared with respect to 'long operating time' as shown in Tables 3-6. Table 3 shows the responses of 5 participants when they were asked to score the influential elements. As it is shown in Table 4 , by applying pairwiser rules, given scores were converted to pairwise comparisons. Table 5 shows how to transform crisp pairwise comparisons into fuzzy linguistic variables, followed by aggregation of five fuzzy judgments and defuzzification. And finally, Table 6 represents estimated priority vectors of four decision elements whose inconsistency ration is reasonably acceptable (less than 0.1).
It is noteworthy to mention, it is possible to use the super decision software for the purpose of deriving local priority vectors. Decision makers need to enter aggregated defuzzified outputs into the Matrix tab of software since the outputs are usually decimal numbers. This software is not only helpful for this purpose, it can also raise a huge supermatrix to power in order to estimate final priority of decision alternatives with higher reliability and accuracy. Therefore, all the estimated priority vectors were transferred in the corresponding supermatrix cells, and the software formed column stochastic and finally computed limit supermatrix. Figure 4 shows the limit supermatrix of this case study when the superdecision was employed. The overall priority of decision alternatives with respect to goal in three different formants: raw, normalized and idealized are shown in Table 7.

Table 3. Scoring on the scale of pairwiser

\begin{tabular}{lccccc}
\hline \multirow{2}{*}{ wrt LOT } & \multicolumn{5}{c}{ Crisp Score } \\
\cline { 2 - 6 } & E1 & E2 & E3 & E4 & E5 \\
\hline SBD & 9 & 8 & 9 & 9 & 9 \\
BP & 8 & 7 & 7 & 6 & 7 \\
DBO & 4 & 6 & 6 & 5 & 5 \\
HSC & 4 & 4 & 3 & 5 & 3 \\
\hline
\end{tabular}


Table 4. Conversion from pairwiser to pairwise comparision

\begin{tabular}{|c|c|c|c|c|c|c|c|c|c|c|}
\hline \multirow{2}{*}{ wrt LOT } & \multicolumn{5}{|c|}{ DBO } & \multicolumn{5}{|c|}{ HSC } \\
\hline & E1 & E2 & E3 & E4 & E5 & E1 & $\mathrm{E} 2$ & E3 & $\mathrm{E} 4$ & E5 \\
\hline SBD & 0.1667 & 0.333 & 0.25 & 0.2 & 0.2 & 0.1667 & 0.2 & 0.142 & 0.2 & 0.142 \\
\hline $\mathrm{BP}$ & 5 & 2 & 2 & 2 & 3 & 0.2 & 0.25 & 0.2 & 0.5 & 0.2 \\
\hline $\mathrm{DBO}$ & 1 & 1 & 1 & 1 & 1 & 1 & 0.33 & 0.25 & 1 & 0.33 \\
\hline \multirow[t]{2}{*}{ HSC } & & & & & & 1 & 1 & 1 & 1 & 1 \\
\hline & \multicolumn{5}{|c|}{ SBD } & \multicolumn{5}{|c|}{ BP } \\
\hline & E1 & E2 & E3 & $\mathrm{E} 4$ & E5 & E1 & $\mathrm{E} 2$ & E3 & $\mathrm{E} 4$ & E5 \\
\hline SBD & 1 & 1 & 1 & 1 & 1 & 0.5 & 0.5 & 0.333 & 0.25 & 0.33 \\
\hline BP & & & & & & 1 & 1 & 1 & 1 & 1 \\
\hline
\end{tabular}

Table 5. Linguistic pairwise comparisons

\begin{tabular}{|c|c|c|c|c|c|c|c|}
\hline \multirow{3}{*}{ wrt LOT } & E1 & E2 & E3 & $\mathrm{E} 4$ & E5 & $\begin{array}{c}\mathrm{GM}=\left(\tilde{a} \mathrm{i} j \mathrm{1} 1^{* a ̃ i j}\right. \\
2 * a \tilde{a} \mathrm{j} 3^{* a \tilde{i} j} 4 * a \tilde{a} i j \\
5)^{\wedge} 1 / 5\end{array}$ & $\begin{array}{c}\mathrm{a}=\mathrm{L} i j+(\mathrm{U} i j- \\
\mathrm{L} i j+\mathrm{T} i j-\mathrm{L} i j) / 3\end{array}$ \\
\hline & \multicolumn{5}{|c|}{ ãij=(Lij,Tij,Uij) } & $\tilde{a} i j=(L i j, T i j, U i j)$ & aij \\
\hline & & & DBO & & & Aggregated & Defuzzifiied \\
\hline SBD & $(1 / 7,1 / 6,1 / 5)$ & $(1 / 4,1 / 3,1 / 2)$ & $(1 / 5,1 / 4,1 / 3)$ & $(1 / 6,1 / 5,1 / 4)$ & $(1 / 6,1 / 5,1 / 4)$ & $(0.182,0.223,0.291)$ & 0.232 \\
\hline $\mathrm{BP}$ & $(4,5,6)$ & $(1,2,3)$ & $(1,2,3)$ & $(1,2,3)$ & $(2,3,4)$ & $(0.274,0.384,0.660)$ & 0.439 \\
\hline $\mathrm{DBO}$ & $(1,1,1)$ & $(1,1,1)$ & $(1,1,1)$ & $(1,1,1)$ & $(1,1,1)$ & $(1,1,1)$ & 1.000 \\
\hline wrt LOT & & & SBD & & & & \\
\hline SBD & $(1,1,1)$ & $(1,1,1)$ & $(1,1,1)$ & $(1,1,1)$ & $(1,1,1)$ & $(1,1,1)$ & 1.000 \\
\hline wrt LOT & & & HSC & & & & \\
\hline SBD & $(1 / 7,1 / 6,1 / 5)$ & $(1 / 6,1 / 5,1 / 4)$ & $(1 / 8,1 / 7,1 / 6)$ & $(1 / 6,1 / 5,1 / 4)$ & $(1 / 8,1 / 7,1 / 6)$ & $(0.259,0.354,0.574)$ & 0.172 \\
\hline $\mathrm{BP}$ & $(1 / 6,1 / 5,1 / 4)$ & $(1 / 5,1 / 4,1 / 3)$ & $(1 / 6,1 / 5,1 / 4)$ & $(1 / 3,1 / 2,1)$ & $(1 / 6,1 / 5,1 / 4)$ & $(1,1,1)$ & 0.266 \\
\hline $\mathrm{DBO}$ & $(1,1,1)$ & $(1 / 4,1 / 3,1 / 2)$ & $(1 / 5,1 / 4,1 / 3)$ & $(1,1,1)$ & $(1 / 4,1 / 3,1 / 2)$ & $(0.259,0.354,0.574)$ & 0.504 \\
\hline HSC & $(1,1,1)$ & $(1,1,1)$ & $(1,1,1)$ & $(1,1,1)$ & $(1,1,1)$ & $(1,1,1)$ & 1.000 \\
\hline wrt LOT & & & $\mathrm{BP}$ & & & & \\
\hline SBD & $(1 / 3,1 / 2,1)$ & $(1 / 3,1 / 2,1)$ & $(1 / 4,1 / 3,1 / 2)$ & $(1 / 6,1 / 5,1 / 4)$ & $(1 / 4,1 / 3,1 / 2)$ & $(0.259,0.354,0.574)$ & 0.396 \\
\hline $\mathrm{BP}$ & & $(1,1,1)$ & $(1,1,1)$ & $(1,1,1)$ & $(1,1,1)$ & $(1,1,1)$ & 1.000 \\
\hline
\end{tabular}




\begin{tabular}{cccc}
\hline Table 6. & \multicolumn{2}{l}{ Estimated priority vectors } \\
\hline \multirow{3}{*}{ Inconsistency $\mathbf{0 . 0 1 1 9}$} \\
\cline { 2 - 4 } & Name & Normalized & Idealized \\
\cline { 2 - 4 } wrt LOT & HSC & 0.0745 & 0.1381 \\
& SBD & 0.5395 & 1.0000 \\
& BP & 0.2586 & 0.4794 \\
\hline
\end{tabular}

Table 7. Final priority of alternatives

\begin{tabular}{|c|c|c|c|c|}
\hline \multirow{12}{*}{ 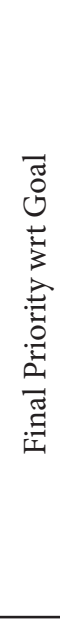 } & Name & Ideals & Normal & Raw \\
\hline & $1 \mathrm{EXT}$ & 0.737571 & 0.134399 & 0.04595 \\
\hline & $2 \mathrm{OCHO}$ & 0.655246 & 0.119398 & 0.040822 \\
\hline & $3 \mathrm{ABD}$ & 0.545451 & 0.099391 & 0.033981 \\
\hline & $4 \mathrm{ASU}$ & 0.246349 & 0.044889 & 0.015347 \\
\hline & $5 \mathrm{SSD}$ & 1 & 0.182218 & 0.0623 \\
\hline & $6 \mathrm{MD}$ & 0.037503 & 0.006834 & 0.002336 \\
\hline & 7 CPUA & 0.743855 & 0.135544 & 0.046342 \\
\hline & 8 IHS & 0.683233 & 0.124497 & 0.042565 \\
\hline & 9 NPIX & 0.335016 & 0.061046 & 0.020871 \\
\hline & $10 \mathrm{SSD}$ & 0.200021 & 0.036447 & 0.012461 \\
\hline & $11 \mathrm{BT}$ & 0.303689 & 0.055338 & 0.01892 \\
\hline
\end{tabular}

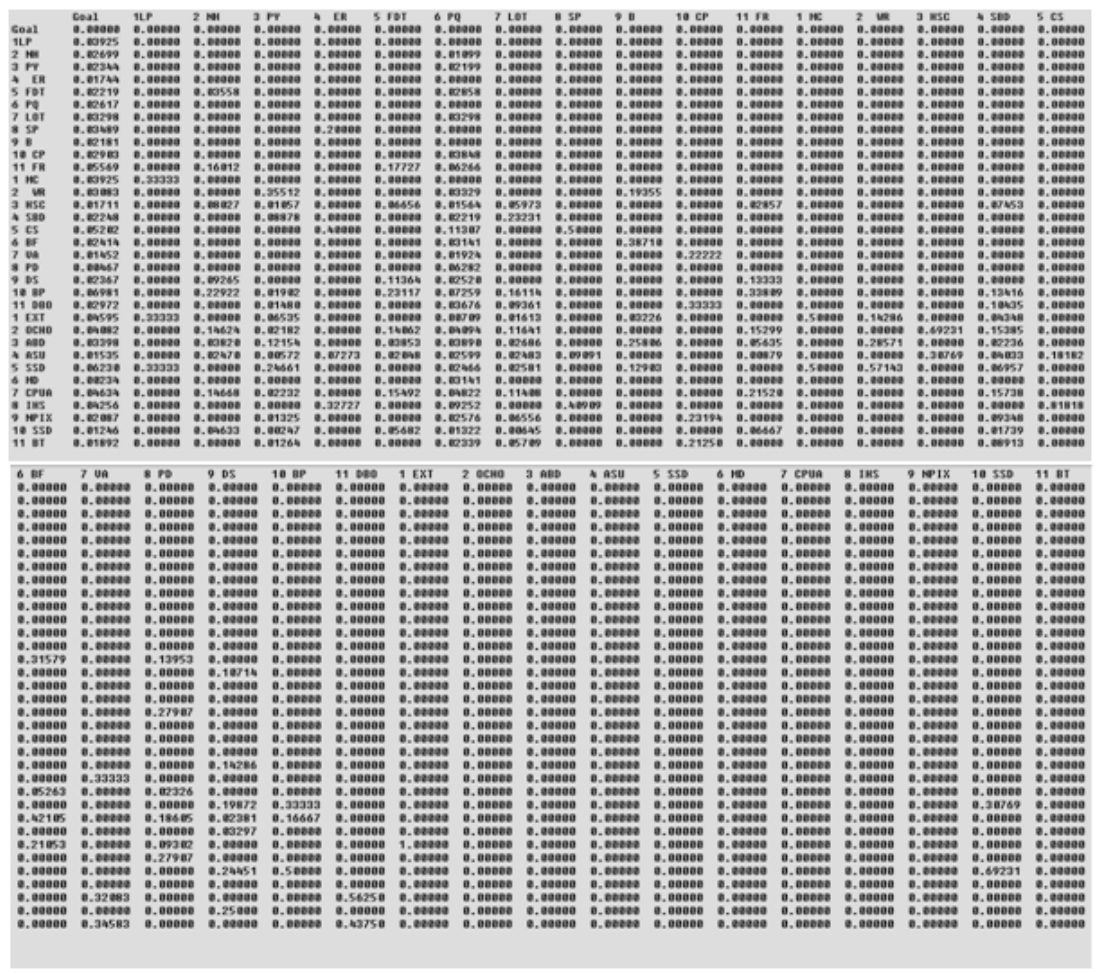

Figure 4. The limit super matrix of case study.

\section{Conclusion and Recommendation}

The methodology of this paper was developed for the first two stages of a four-phase model, namely, product planning and parts deployment. However, this methodology is able to cover all four phases, if extended. In this paper, a new ANP based extension was proposed for QFD in response to two major bottlenecks: the problem or difficulty of data collection, and the possibility of receiving inconsistent judgments when ANP is utilized to model a QFD with large number of components. These two issues led our research team to introduce a fuzzy cybernetic ANP as a new extension for QFD in which subjectivity of judgments is handled by applying fuzzy set theory. In this regard, for the proposed case study, instead of performing 130 pairwise comparisons, experts were asked to answer only 66 
questions which significantly facilitate data collection process. Furthermore, while there are two ways to estimate final priority of decision alternatives, a careful selection should be made in order to select either supermatrix or simple matrix manipulation method. Although, simple matrix manipulation is more popular, supermatrix approach is more versatile and able to analysis more complex models. Nevertheless, it is less favourable when there are many inner-dependence between QFD elements. The reason behind is, in the second or third cycle of rising weighted supermatrix into power, priority of decision alternatives shifts to zero. Therefore, in such cases, it is recommended to use simple matrix manipulation method. In addition, this research used triangular fuzzy numbers whose membership function was adapted from previous research. Researchers are encouraged to apply other types of fuzzy numbers, such as trapezoidal or bell shape fuzzy numbers together with a proper membership function.

\section{Acknowledgement}

This research was financially supported by Universiti Teknologi Malaysia (GUP reference number PY/2012/00304), and the scholarship offered by Islamic Azad University, Fouman and Shaft Branch. The authors would like to express their gratitude to the above mentioned universities for their assistance and support, provided to the authors during the time of research.

\section{References}

1. Shahraki AR, Paghaleh MJ. Ranking the voice of customer with fuzzy DEMATEL and fuzzy AHP. Indian J Sci Technol. 2011; 4(12):1763-1772.

2. Akao Y. Quality function deployment: integrating customer requirements into product design. Cambridge, Mass: Productivity Press; 1990.

3. Mehrjerdi YZ. Quality function deployment and its extensions. Int J Qual Reliab Manag. 2010; 27(6):616-640.

4. Liu HT, Tsai YL. A fuzzy risk assessment approach for occupational hazards in the construction industry. Safety Sci. 2012; 50(4):1067-1078.

5. Karsak EE, Sozer S, Alptekin SE. Product planning in quality function deployment using a combined analytic network process and goal programming approach. Comput Ind Eng. 2003; 44(1):171-190.
6. Hauser J, Clausing D. The house of quality. Harvard Bus Rev. 1988; 66(3):63-73.

7. Chan LK, Wu ML. Quality function deployment: a comprehensive review of its concepts and methods. Qual Eng. 2002;15(1):23-35.

8. Liu HT, Wang CH. An advanced quality function deployment model using fuzzy analytic network process. Appl Math Model. 2010; 34(11):3333-3351.

9. Ho W. Integrated analytic hierarchy process and its applications-a literature review. Eur J Oper Res. 2008; 186(1):211-228.

10. Partovi FY, Corredoira RA. Quality function deployment for the good of soccer. Eur J Oper Res. 2002; 137(3): 642-656.

11. Partovi FY. A quality function deployment approach to strategic capital budgeting. Eng Economist. 1999; 44(3): 239-260.

12. Saaty T. The analytic network process. Iranian Journal of Operations Research. 2008; 1(1):1-27.

13. Büyüközkan G, Ertay T, Kahraman C, Ruan D. Determining the importance weights for the design requirements in the house of quality using the fuzzy analytic network approach. Int J Intel Syst. 2004; 19(5):443-461.

14. Chung SH, Lee AH, Pearn WL. Analytic Network Process (ANP) approach for product mix planning in semiconductor fabricator. Int J Prod Econ. 2005; 96(1): 15-36.

15. Ertay T, Büyüközkan G, Kahraman C, Ruan D. Quality function deployment implementation based on analytic network process with linguistic data: an application in automotive industry. J Intel Fuzzy Syst. 2005; 16(3): 221-232.

16. Kahraman C, Ertay T, Büyüközkan G. A fuzzy optimization model for QFD planning process using analytic network approach. Eur J Oper Res. 2006; 171(2): 390-411.

17. Lami IM, Vitti EL. A combination of quality function deployment and analytic network process to evaluate urban redevelopment projects: an application to the Belle de Mai-La Friche of Marseille, France. Journal of Applied Operational Research. 2011; 3(1):2-12.

18. Lee AH, Kang HY, Yang CY, Lin CY. An evaluation framework for product planning using FANP, QFD and multi-choice goal programming. Int $\mathrm{J}$ Prod Res. 2010; 48(13):3977-3997.

19. Lee YT, Wu W, Tzeng GH. An effective decisionmaking method using a combined QFD and ANP approach. WSEAS Transactions on Business and Economics. 2008; 12(5):541-551.

20. Pal DK, Ravi B, Bhargava LS. Rapid tooling route selection for metal casting using QFD-ANP methodology. Int 
J Computer Integrated Manufacturing. 2007; 20(4): 338-354.

21. Asan U, Soyer A, Serdarasan S. A fuzzy analytic network process approach. In: Kahraman C, editor. Computational Intelligence Systems in Industrial Engineering. Atlantis Press; 2012. p. 155-179.

22. Saaty TL. The analytic hierarchy and analytic network measurement processes: applications to decisions under risk. European Journal of Pure and Applied Mathematics. 2007; 1(1):122-196.

23. Lee $\mathrm{AH}$, Lin CY. An integrated fuzzy QFD framework for new product development. Flex Serv Manuf J. 2011; 23(1):26-47.
24. Klir GJ, Yuan B. Fuzzy sets and fuzzy logic: theory and applications. Upper Saddle River, New Jersey: Prentice Hall, PRT; 1995.

25. Saaty TL. The analytic hierarchy process: planning, priority setting, resources allocation. 2nd ed. Pittsburg, PA: McGraw-Hill; 1980.

26. Liu R, Yu JX, Sun HC, Tian P. Introduction to the ANP super decisions software and its application. Systems Engineering-theory \& Practice. 2003; 8:024.

27. Chen Z. A cybernetic model for analytic network process. 2010 International Conference on Machine Learning and Cybernetics (ICMLC); 2010 Jul 11-14; Qingdao, China. IEEE: New York. 2010. p. 1914-1919. 